\title{
AN IMAGE-BASED MODELING EXPERIENCE ABOUT SOCIAL FACILITIES, BUILT DURING THE FASCIST PERIOD IN MIDDLE ITALY
}

\author{
D. Rossi
}

Scuola di Architettura e Design “E. Vittoria”, Università di Camerino

KEY WORDS: Modeling, Reconstruction, Visualization, Heritage documentation, Image-based modeling, Survey

\begin{abstract}
:
The main focus of this article is to explain a teaching activity. This experience follows a research aimed to testing innovative systems for formal and digital analysis of architectural building. In particular, the field of investigation is the analytical drawing. An analytical draw allows to develope an interpretative and similar models of reality; these models are built using photomodeling techniques and are designed to re-write modern and contemporary architecture. The typology of the buildings surveyed belong to a cultural period, called Modern Movement, historically placed between the two world wars. The Modern Movement aimed to renew existing architectural principle and to a functional redefinition of the same one. In Italy these principles arrived during the Fascist period. Heritage made up of public social buildings (case del Balilla, G.I.L., recreation center...) built during the fascist period in middle Italy is remarkable for quantity and in many cases for architectural quality. This kind of buildings are composed using pure shapes: large cube (gyms) alternate with long rectangular block containing offices creates compositions made of big volumes and high towers. These features are perfectly suited to the needs of a surveying process by photomodeling where the role of photography is central and where there is the need to identify certain and easily distinguishable points on all picture, leaning on the edges of the volume or lininig on the texture discontinuity. The goal is the documentation to preserve and to develop buildings and urban complexes of modern architecture, directed to encourage an artistic preservation.
\end{abstract}

\section{INTRODUCTION}

\subsection{The competition and the teaching experience}

In October 2009, the UIA (International Union of Architects), has opened an international competition aimed exclusively to Architecture students for the production of digital threedimensional models, related to significant buildings constructed during the twentieth century, obtained by means of image based on modeling techniques*.

The goal of such experience was to catch the attention of those who were going to deal with architectural heritage in the future, by giving them the opportunity for enriching the archive of the buildings of the twentieth century, which have been properly classified by the UIA itself and by the Do.Co.Mo.Mo.

In the past decades, the architectural heritage related to the Modern Movement has been reportedly in danger more than in other times.

During the end of 80 's many architectural masterpieces were demolished or strongly modified. That happened because they had not previously been classified as significant buildings and their importance had not been therefore recognized. This could have been avoided and their original style, structure and function could have been properly restored. Such Architectural heritage is important both for its quantity of buildings and for their quality in some cases. That is not surprising if we think the fascism had obtained a huge political power during that period. The regime used to control everything, even the education of the population, especially the youth. Being the Architecture a strong mean of communication, the second reason of such an architectural heritage is to be found in the fact that fascism used it as a publicity of its political campaign.

Young and brilliant architects were employed and asked to work
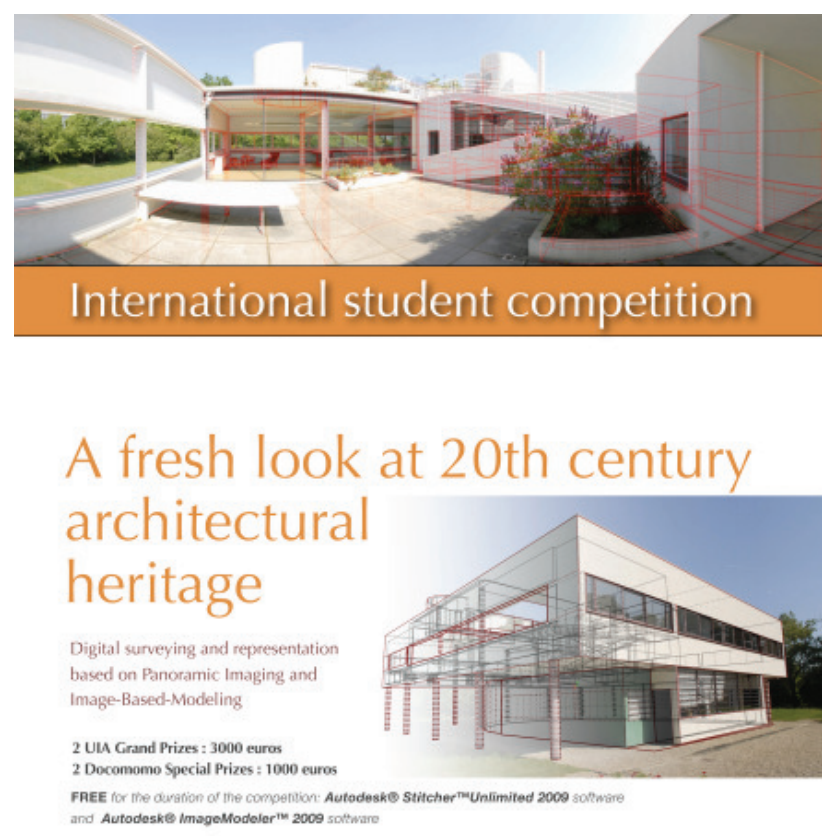

Figure 1. Poster of International competition for the production of digital three-dimensional models obtained by means of image based modeling techniques.

on experimental projects which were characterized by new and modern typologies and architectural languages. Although all the buildings could easily look alike, there were differences from one to another, in terms of importance of their Architect or their Period of construction but in the following years the principles of modern architecture lost their influence going towards a more and more sterile monumentality.

\footnotetext{
* The call is available at website http://www.3d20th.archi.fr/
} 


\section{Building tipologies}

The UIA Competition offered the students and their teachers not only the opportunity of studying interesting buildings and their own history but also from an educational point of view, it was an useful experience for the former ones to learn more about The Modern Movement, its origins and the stylistic features throughout time and geographic places over our Country.

In some cases, when trying to operate on one of those unique buildings the local administration took the wrong decisions and the lack of cultural and historical knowledge made things worse. Even if the purpose was to restore the structure and re-use the building with a different function than its original one, a superficial choice was made and the structure was often demolished.

As a result of all this, some buildings, originally called "Case del Balilla" or "G.I.L." (Gioventù Italiana del Littorio) buildings became "Ex-Case del Balilla" or "Ex-GIL" because of a total loss of their existing typology or function.

In a few cases, the architects took into consideration the idea of re-using the buildings as schools so that they had similar functions and typology to the original ones allowing them to keep the structure. In some other cases the original function, the quality of internal large and open spaces were not kept at all, losing potential ideas of a different project.
In terms of architectural elements all the buildings surveyed are made of pure forms such as great square spaces or large boxes for gyms, long parallelepipeds with offices and all these components together form primary volumes in which semi-cylindrical and tall towers work as symbolic links where alternative full and empty take place of ornaments. The walls are smooth and the rhythm of façades is given by great windows without frames or gables.

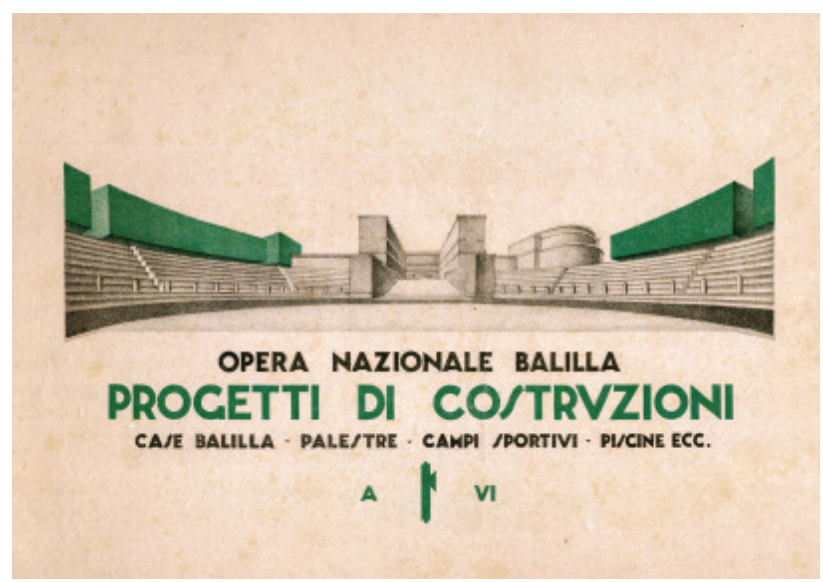

Figure 2. Manual on how to build social facilities, Enrico Del Debbio, 1928
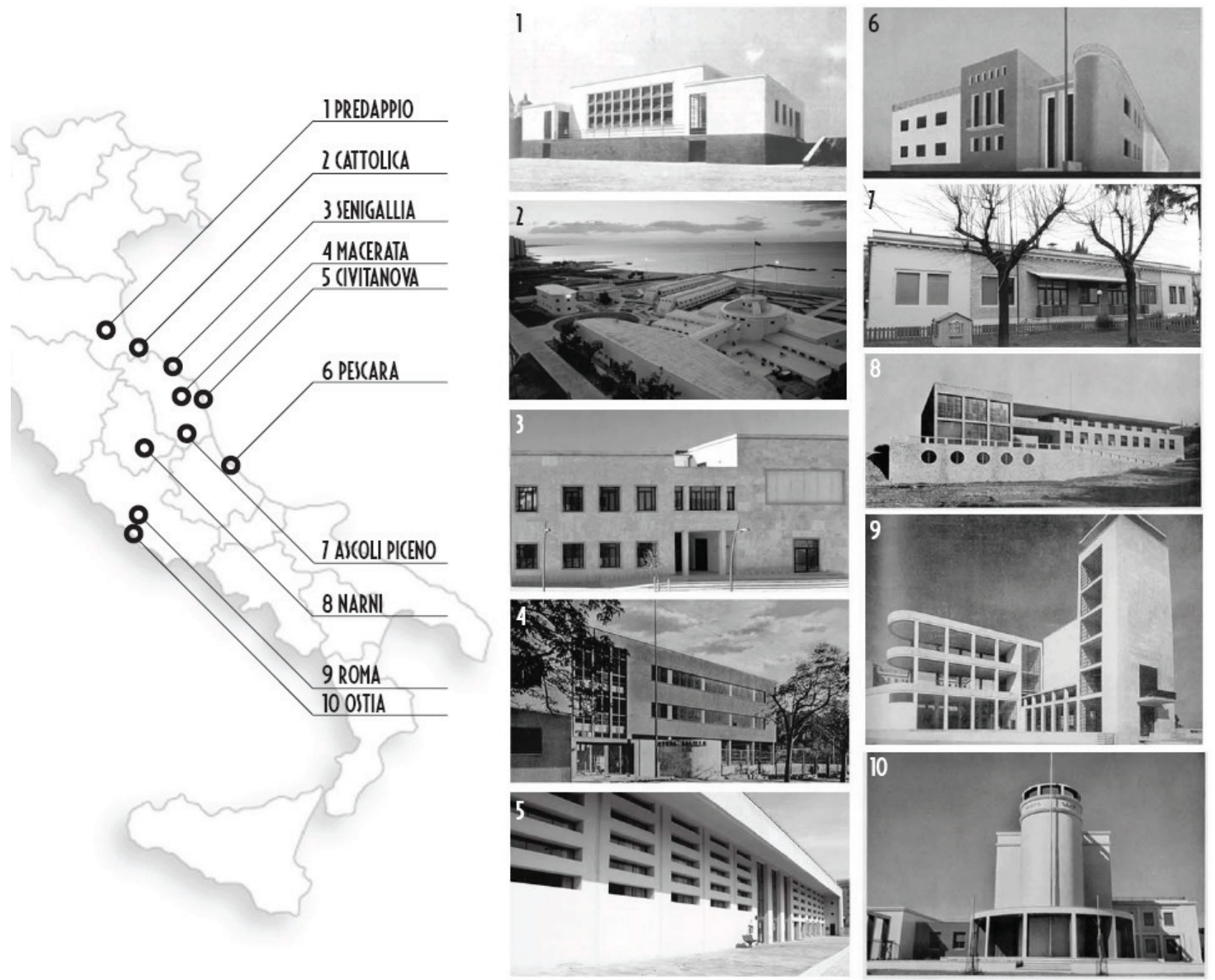

Figure 3. Geographical location of buildings surveyed 
Even though concrete structural frames gave planners chances to design great spaces and roofs for gyms, auditoriums, the coating materials the architects used were rather traditional, such as marble and bricks for bichromatic façades.

From a pratical point of view, these features are ideal for a digital image-based modeling process in which the role of a good photo shooting sequence is the main issue and where the need of finding reference points is very important when going to match the photos sharing corners or other elements. A large number of images is therefore needed in order to complete

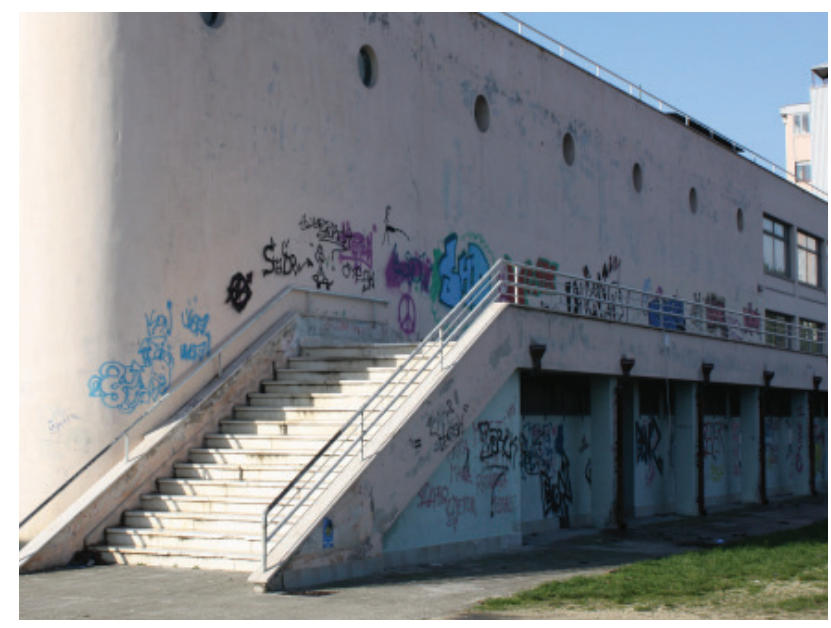

Figure 4. Casa del Balilla in Civitanova (MC): graffiti on the façade

the photo capture so it is rather important to catch the three dimension spaces by finding quadrangular holes on façades or among their material discontinuities. The major difficulties have been found when the students tried to deal with cylindrical elements or generally with circular shapes. It was extremely difficult to find points of discontinuity. In this specific case, the students were forced to use easier methods such as graffiti or fake signs of degradation. It was sometimes necessary to put additional temporary markers on the building hoping to help the photo modeling program run properly and recognize the points themselves.

Another problem was related to the scale of the buildings. For obvious reasons, they were not to be too tall in order to avoid long pictures from being manually modified afterwards. Moreover, once the students succeeded in obtaining a good $3 \mathrm{~d}$ model from the Image Modeler, the next step was to take the

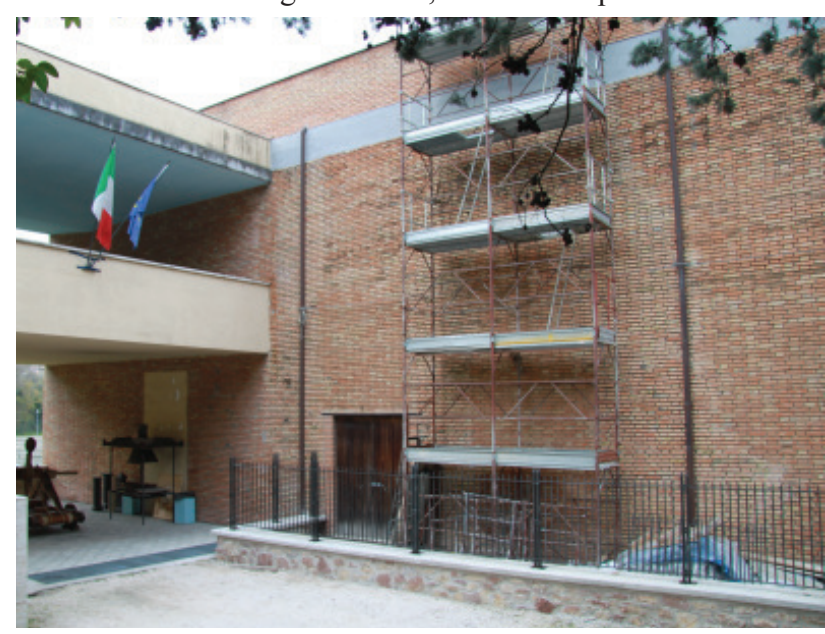

Figure 5. G.I.L. building in Narni (TR): presence of a scaffold textures of the materials from the photos and apply them to the previous model. That was why the first phase had to be fulfilled well being the following ones even more precise and by that time it was absolutely important for the program to have had previously a good calibration.

If the building was tall however, students were allowed to reach the closest ones and shoot photos from higher points. When this was not possible, additional pictures were needed for details on the roof in order to integrate the photo modeling with more polygons. This method allowed the students to "fill" holes that could show wrong depth. The regular forms and façades made it possible to obtain good results.

Before starting working with the program though, students were asked to investigate the location of the building and the

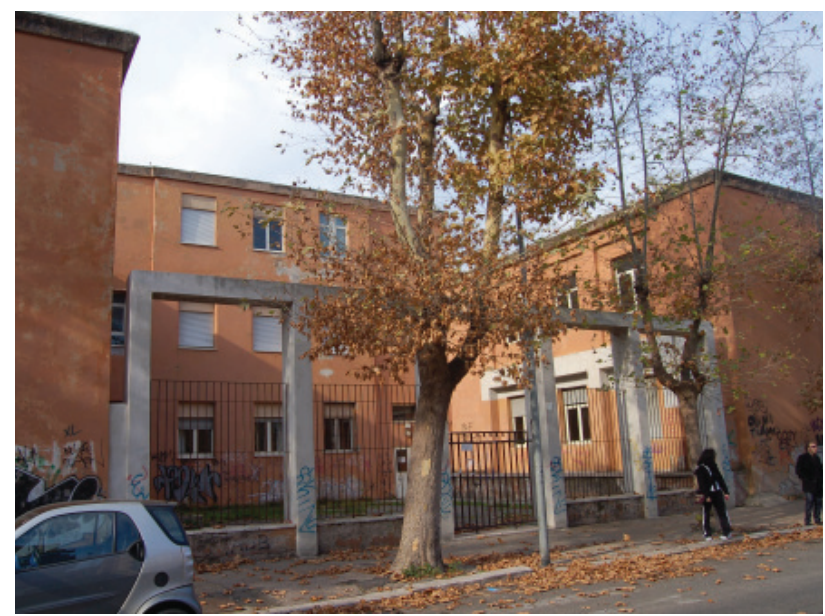

Figure 6. G.I.L. building in Ostia (RM): presence of trees in front of the façade

surroundings to see if trees, or any other obstacles could give them problems when going to calibrate it. They could also make sure that they would be able to access the structures and shoot photos of the spaces inside. Once the visit was done, we made a list of the potential difficulties/problems and found a specific solution for each of them. The second time would be dedicated to collect as many photos as possible, going around the building and shooting a sequence of pictures that would be selected one by one afterwards.

During this exercise, it was very important for the students not to step back when doing the photos, even if they had forgot something, it had to be done in a precise and continuous way. This method was to be applied by the students not only for formal and professional reasons, but also because whoever happened to work or see those pictures, they would be perfectly comprehensible.

List of buildings surveyed:
G.I.L., 1935
G.I.L., 1935
G.I.L., 1939
G.I.L., 1939
Casa del Balilla, 1935
Casa del Balilla, 1936
Casa del Balilla, 1939
Casa del Balilla, 1940
Colonia Marina, 1934
O.N.M.I, 1938 


\section{IMAGE-BASED MODELING METHOD}

Although the use of photos to measure and represent reality is not a new solution, we can assume that the process of photo modeling is a brand new approach to many possibilities of dealing with only one method unifying different technical phases, allowing us to achieve the plasticity of any kind of objects, in a way that we could define as "direct", thanks to automatic calculations ran by digital devises that use are based on photography, which is an easy, direct, mobile and economic tool. All this method mentioned above consists of four different logical moment of whom only the first one ends on the site:

- the shooting phase of the building/object;

- the orientation of every single photogram taken in a reference space;

- the elaboration of a three-dimensional model

- the texturing phase of it with measurements and textures of the real coating material

\subsection{Photographic campaign}

After initially knowing what morphological complexity we had to work on through technical drawings and historical photos, the real shooting campaign was planned in order to find out how many pictures of the building we did need for a global capture of it, including indoor spaces. Being the aim of photo modeling the detection of the morphological and stylistic characteristics of the subject/object studied, it is important to have a good knowledge and understanding of the basics of photography and to be able to catch the best potential frames of a scene, especially the relations of the different parts of the building. In order to find a point in the $3 \mathrm{D}$ space all is needed is for that point to be visible at least in two convergent images, knowing that the next steps will be mainly made on a large number of previous points to be used as "snap" on which to attach angles and façades. It is important to use the same photo camera with the same focal length and a constant distance from the subject as if we were drawing an ideal circle around it. In our experience most of the analyzed structures were surrounded by driveways with car parkings or rows of trees. Such obstacles have been removed before starting the photo modeling procedure in order to avoid them to appear on the façades applying textures on them. The removal however was not possible in the calibration phase and the obstacles remained hiding useful reference point. This happened especially with the bottom corners of the buildings which made it necessary to try and find other solutions. Another problem during the shooting campaign was that sometimes there was not enough space or just narrow roads to get the whole part in it. When this happened many images of the same detail were made in order to "stitch" them afterwards. Last but not least, some measurements were taken in the three main directions verifying some conditions of perpendicularity between the surfaces so that a reference Cartesian system could be taken into consideration in the $3 \mathrm{D}$ scene.

\subsection{Orientation of the cameras}

When the shooting campaign was completed and all the photos collected, it was time to start the second phase which took more time, and consisted in getting the right orientation of the cameras, then finding the geometrical models of the photo cameras in the $3 \mathrm{D}$ scene and the calculation with the related distortion of the images produced by the photo camera.

This method was followed using the PhotoModeling software ImageModeler2009 by Autodesk which is based on a whole of

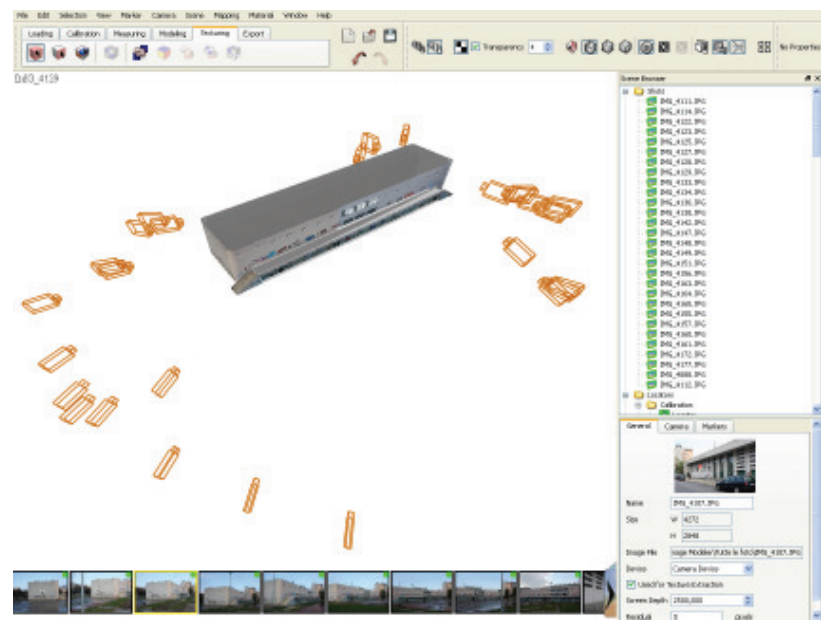

Figure 7. Casa del Balilla in Civitanova (MC): screenshot from Autodesk Image modeler 2009

homologous points taken from two or more frames and by the collinear condition between the optical centre of the camera (point in the photo that is expressed in image coordinates and point in the $3 \mathrm{D}$ scene expressed in spatial coordinates), allows to orientate photos and on the other hand it allows to find several points (locators), useful for the next modeling phase.

\subsection{Modeling}

After having well oriented several frames and having collected a good number of descriptive locators of the main reference points belonging to the most representative elements on façades, the
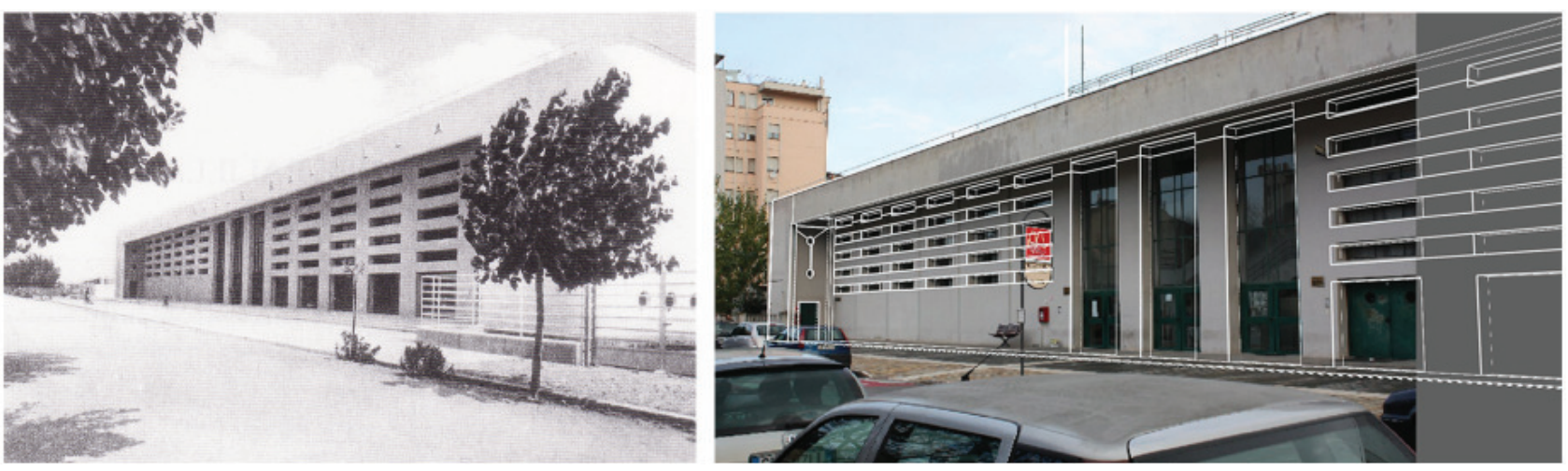

Figure 8. Casa del Balilla in Civitanova (MC): comparison of the original building (left) with the 3D model 
next step was to elaborate the digital three-dimensional model. The construction of such a model represent a moment of criticism and comprehension of the spatial intelligence of the architectonic text; a meditation that has to be taken as a chance to have an interpretation of the different parts and their relations but also to find and classify the stylistic details of components. The choice of the buildings to analyze was made on the ones with a well defined volume, although we had to evaluate them

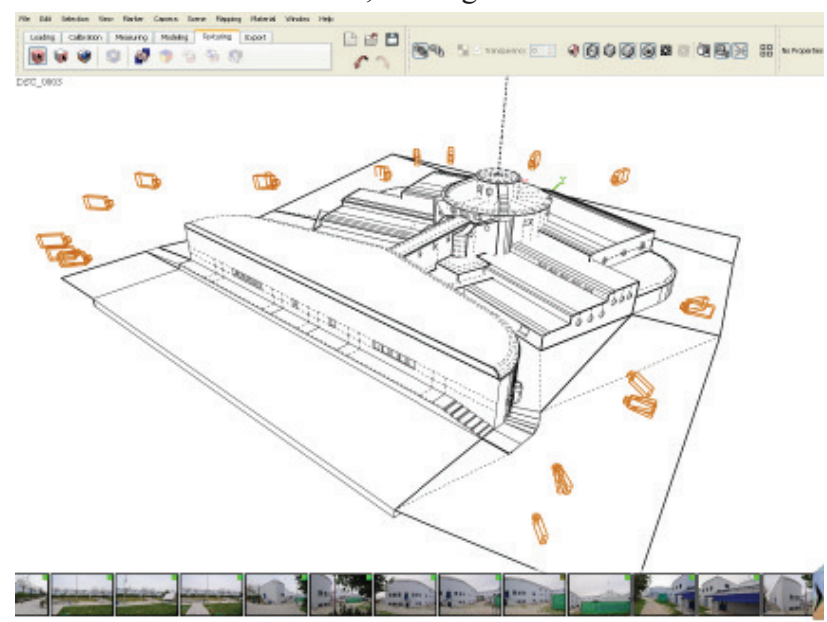

Figure 9. Colonia marina in Cattolica $(\mathrm{RN})$ : screenshot from Autodesk Image modeler 2009

through a modeling phase based on different editing operations made on meshes which were to fit the entire composition. Such operations belong to a repertory which could be defined as polygonal modeling. A polygonal surface is composed by a collection of sides, vertexes and polygons connected with each other so that each side is at least common between two polygons. A side connects two vertexes and one polygon is a sequence of closed sides. Although it is possible to build a polygonal mesh finding manually vertexes one by one, the sequence of necessary actions for elaborating a model usually starts by defining the primary surfaces that characterize the shell of the studied object. These surfaces are defined from different fixed locators during the orientation phase of the frames and they lay on four vertexes at the edge of each side. In this way, surface by surface, we achieve a rough volume of the model.

Such primitive model represent the starting point for the application for some editing operations, basically three: subdivision, extrusion and smoothing.

Subdivide operations allow to put a series of inner vertexes in an edge of a polygon, to define new edges and brand new polygons. This was essentially the procedure to cut different holes, door or windows laying on the primary surfaces, using as snap points additional locators taken from photos and placed on the corners of the holes themselves. Once the surface was defined and divided, next step was to extrude the new polygons, pushing in or pulling out them according to our need. The extrusion generated a new surface having the same measures of the previous one, connected through new polygons perpendicular to the polygonal mesh itself.

The smoothing method was based on the cut of the corner between the two faces instead, in order to obtain a new polygon inclined of 45 degrees through a copy of the corner itself. This was needed when trying to obtain cylindrical forms from parallelepipeds, repeating the same actions more and more times. When the elaboration of the model was completed, having previously decided the level of detail to aim at, the next operation was to scale the building, re-dimensioning it according to the main measurements taken on the site during the shooting campaign. Once that was done too, it was possible to verify all the measures by extracting bi-dimensional profiles in order to decline proportional studies or to underline modularity.

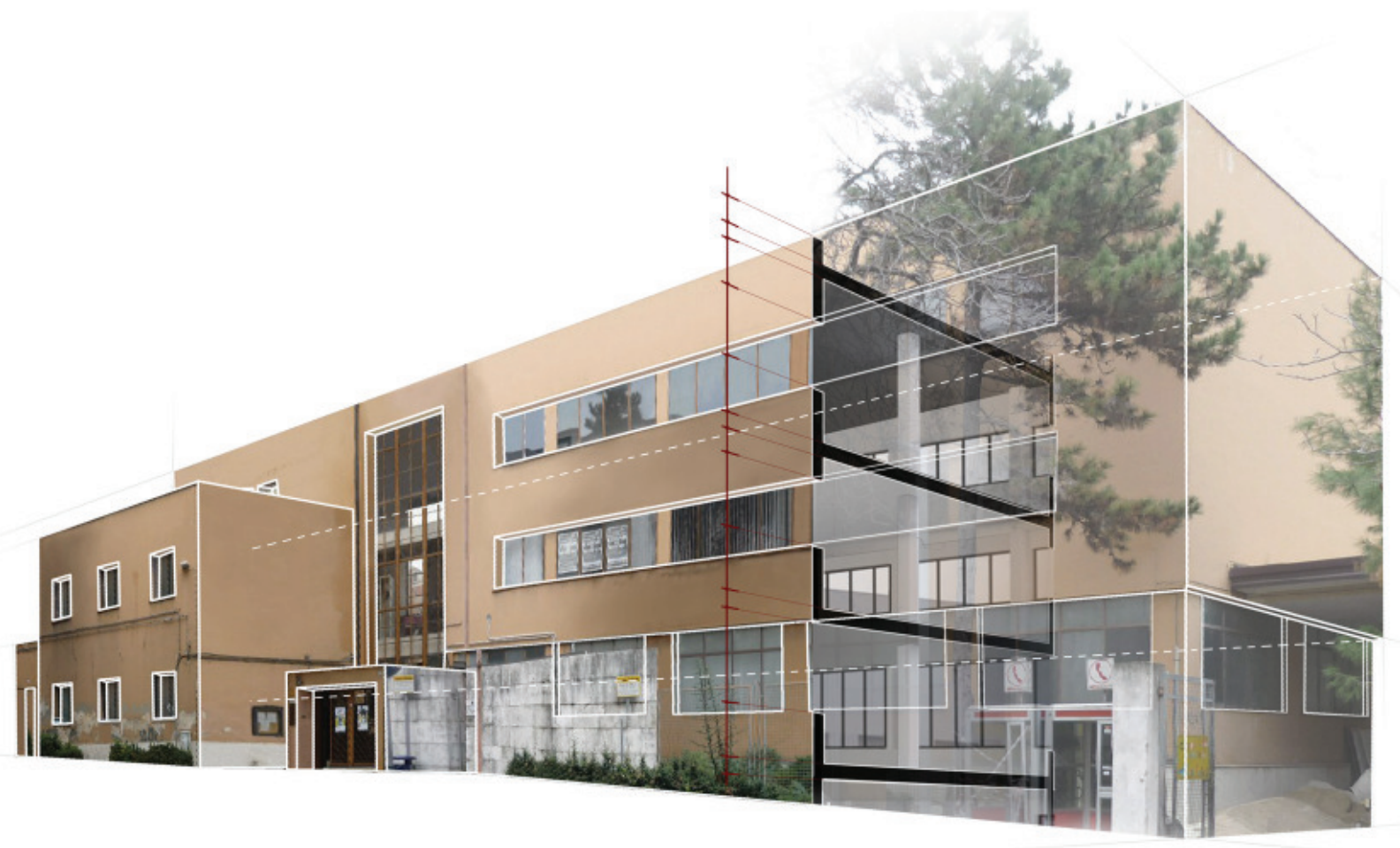

Figure 10. Image based model of G.I.L. building in Macerata 


\subsection{Texturing}

Once the model was constructed, the process of photo modeling was completed with one last phase; the definition of photo metric characteristics of the surfaces through the extraction of some portions of the images oriented for the final mapping of the 3D model "dressing" it up with material textures.

All this final step is about integrating the three dimensional model with a number of bi-dimensional information projecting in terms of collinearity on the polygonal mesh in a three dimensional space (XYZ) a bidimensional image.

Such projections must be repeated for each polygon the $3 \mathrm{~d}$ model is composed by, finding time by time the best photos according to some general rules. The first rule comes from the simple consideration that the best image is that one where the projection on the photo points out the largest region and as a result of that it will have a larger graphic resolution in terms of pixel. One second rule suggests that the best photographic image from which to extract a portion of the mapping is the one that verifies the best conditions of perpendicularity with the studied surface. The more the image shows us an end of the surface the greater will be the mistake due to the righting of the photo.

\section{CONCLUSIONS}

Once this final phase is concluded, the photo modeling process is completed. All the different moments of this process, from the shooting campaign up to the survey of the photometric conditions, passing through the construction of the model have increased step by step the awareness and the spatial knowledge of the studied buildings, allowing their analysis from multiple points of view. First, a direct visit of the site with the photo camera, then the activity in the laboratory aimed to the full three dimensional comprehension of the volumes which the complex is composed by.

The architectural heritage we have considered, as a whole shows signs of deterioration that is not only caused by the time but also by the complex history of their acquisition, maintenance and conversion carried out by the new government.

For these reasons, survey and analysis performed have the meaning of an historical and accurate acquisition, and also these analysis make available heritage information that will be essential to recover many important buildings. The experience also is aimed to define new procedural standards for the acquisition of photo graphics and metric data to develop a three-dimensional digital models to study and analyze existing architectural building, as if it was a technical "manual" to define new standards of knowledge.

Another meaning of this experience was allowing a comparison between different moments of the life of each building or object considered in the study case: the initial state of the project underlined by authentic singed documents, and the actual state, literarily photographed and faithfully displayed.

That made it easier to proceed with verifying and measuring operations of what we could define as a deviation of the buildings as they were builded, from the first technical representation.

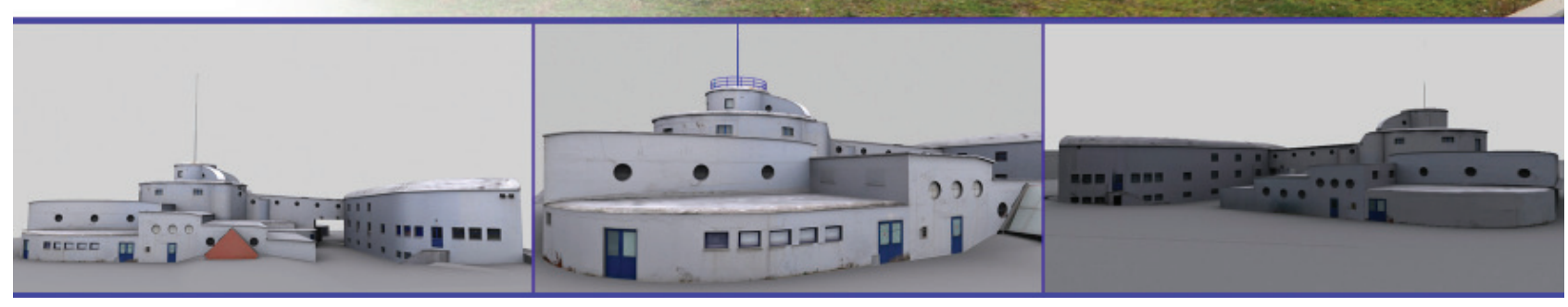

Figure 11. Colonia Marina in Cattolica (RN): image based model 


\section{References:}

Faugeras O. 1993. Three-Dimensional Computer Vision, the MIT press.

Ippoliti E. 2000. Rilevare, Kappa, Roma

Neri M.L. 2003. L'architettura come arte sociale. Nuove immagini urbane per gli edifici a servizio dei cittadini (19261943) in Franchetti Pardo V. L'architettura nelle città italiane del XX secolo. Dagli anni venti agli anni 80, Milano, pp. 346-361.

El-Hakim, S. F., Beraldin, J. A., Picard, M., Godin, G., 2004. Detailed $3 D$ reconstruction of large-scale heritage sites with integrated techniques. IEEE Computer Graphics and Application, 24 (3), pp. 21-29.

Santuccio S. 2005. Le case e il foro. L'architettura dell'ONB, Alinea, Firenze

Neri M.L. 2006, Enrico Del Debbio, Idea Books, Roma

De Luca, L., Florenzano, M., Veron, P., 2007. A generic formalism for the semantic modeling and representation of architecture elements. Visual Computer, 23, pp. 181-205.

Capomolla R. Mulazzani M. Vittorini R. 2008. Case del balilla. Architettura e fascismo, Electa, Milano

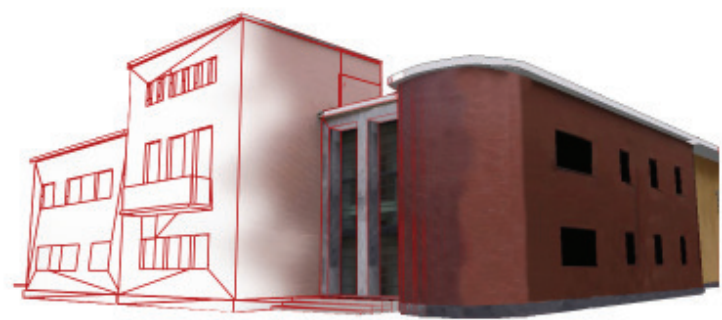

Figure 12. Casa del Balilla in Pescara: image based model

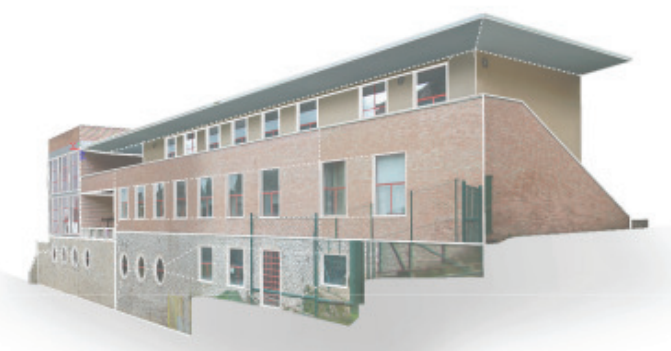

Figure 13. G.I.L. building in Narni (TR): image based model

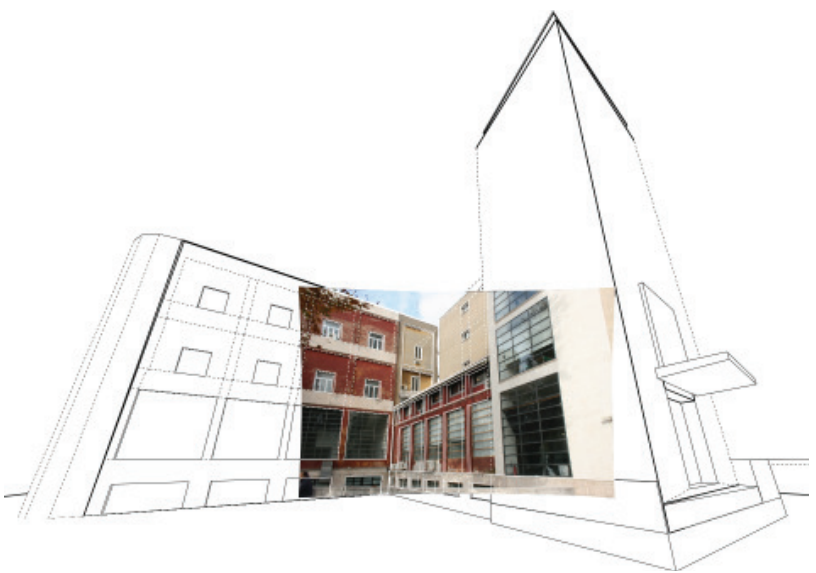

Figure 14. G.I.L. building in Roma: image based model
De Luca L. 2009. Architectural Image-Based surveying, modeling and representation. Methodological reflections and research tracks, in: Portal of Architectural Image-Based Modeling, http://www.map.archi.fr/aibm/Portal_of_Architectural_ImageBased-Modeling/Article-DeLuca2.html (accessed 3 Gen. 2011)

Remondino F. El-Hakim S. Girardi S. Rizzi A. Benedetti S. Gonzo L. 2009. The "3D-ARCH" Project. 3D virtual reconstruction and visualization of complex architectures, in: The International Archives of Photogrammetry, Remote Sensing and Spatial Information Sciences, Vol.38(5/W1)

De Luca L. 2011. La fotomodellazione architettonica, Flaccovio, Palermo

\section{Acknowledgments:}

The present work was developed during the studio workshop in Digital Drawing in the first year of graduate level in Architetcure of the School of Architecture and Design in Ascoli Piceno, University of Camerino. So a special thanks goes to all the students of the Lab. The author also would like to thank prof. Franco Cervellini for his constant support and prof. Maria Luisa Neri for her valuable advice about architectural history.

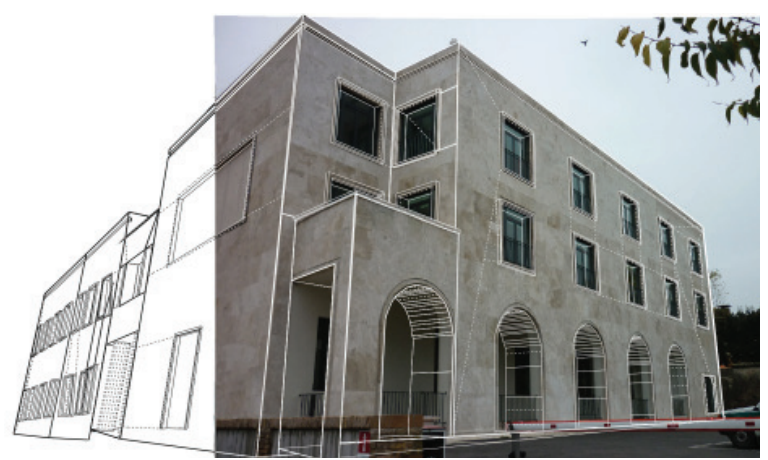

Figure 15. G.I.L. building in Senigallia (AN): image based model

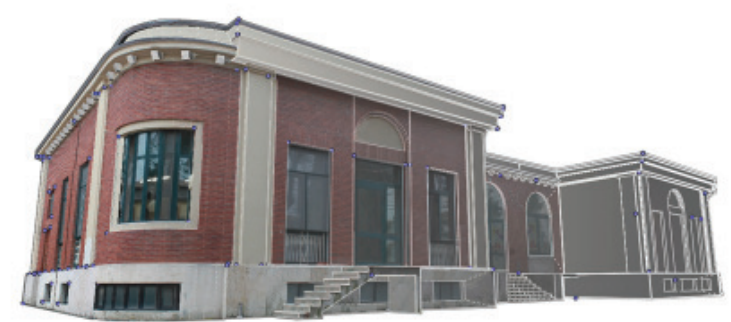

Figure 16. O.N.M.I. building in Ascoli Piceno: image based model

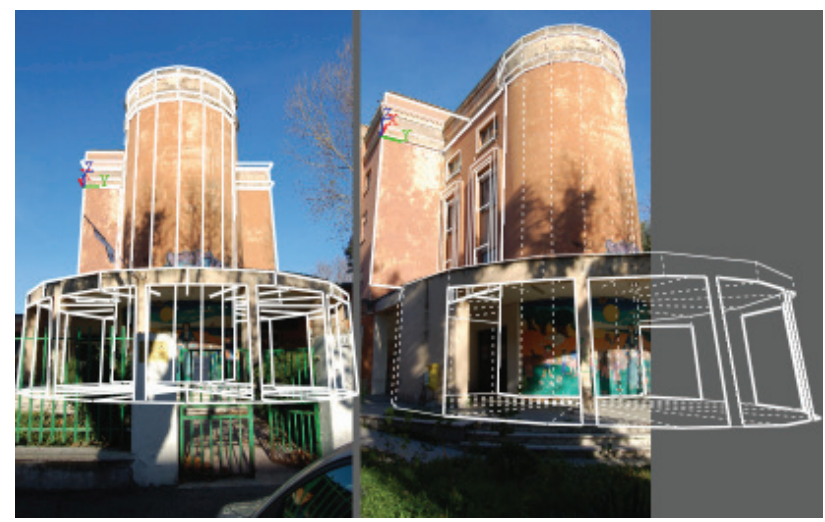

Figure 17. Casa del Balilla in Ostia (RM): image based model 